\title{
Physicians' attitude towards selection of second line therapy with nilotinib and dasatinib in chronic myeloid leukemia patients
}

\author{
Massimo Breccia ${ }^{1}$, Michele Baccarani ${ }^{2}$, Gianantonio Rosti ${ }^{2}$, Francesco Cottone ${ }^{3}$, Laura Cannella ${ }^{3}$, François Guilhot ${ }^{4}$, \\ Marco Vignetti ${ }^{3}$ and Fabio Efficace ${ }^{3^{*}}$
}

\begin{abstract}
We investigated factors that physicians consider of most importance in the selection of second line tyrosine kinase inhibitors treatments (TKIs) in chronic myeloid leukemia patients (CML).
\end{abstract}

Keywords: Chronic myeloid leukemia, Line of therapy, Tyrosine Kinase inhibitors

\section{Letter to the editor}

The use of tyrosine kinase inhibitors (TKIs) dramatically improved the long-term outcomes of patients diagnosed with chronic myeloid leukemia (CML). Imatinib (IMA), the first example of targeted therapy, increased the overall survival up to $85 \%$, both in controlled trial [1] and in real-life settings [2-5]. Second-generation TKIs, dasatinib (DASA) and nilotinib (NILO), were introduced in the armamentarium of active drugs in CML since 2004 after large evidence-based data supported their efficiency for rescuing IMA-resistance or IMA-intolerance in CML patients [6]. Thus far, no optimal sequencing strategy of TKI treatment in CML has been proposed due to the lack of specific comparative clinical trials [7]. Despite several factors, such as drug safety profile, comorbidities or impact on patient's quality of life $[8,9]$, should be considered in the selection of second-line TKI treatment, there is no consensus on the most appropriate drug to use and very little is known on how physicians make these decisions. We conducted a pilot study investigating factors that physicians consider of most importance in treatment allocation to either NILO or DASA as 2nd line treatment allocation after IMA resistance or intolerance.

\footnotetext{
* Correspondence: f.efficace@gimema.it

${ }^{3}$ Italian Group for Adult Hematologic Diseases (GIMEMA), Data Center and Health Outcomes Research Unit, Rome, Italy

Full list of author information is available at the end of the article
}

Data were collected as part of a previously published survey research on CML patients [10]. Analysis is based on a sample of $67 \mathrm{CML}$ patients who switched from IMA to either NILO $(N=36 ; 53.7 \%)$ or DASA $(N=31$; $46.3 \%$ ). The protocol specified that patients had to be in second line treatment for at least 3 months to be eligible for this analysis. In all participating centers, both secondgeneration drugs should have been equally available for use. However, their cost was different, DASA being slightly more expensive. Fifteen physicians were involved in the management of these patients and they were asked to complete an ad-hoc eight-item questionnaire investigating reasons based on which they made the decision to either use one drug over another.

The majority of physicians interviewed were male (80\%) and their median age was 44 years (range 32-62). Participating physicians had a median of 11 years (range 4-32) of experience in treating CML and of 15 years (range 5-35) of overall clinical practice. Twenty-seven percent of them reported to typically meet per week a number of $\mathrm{CML}$ patient between 10 to 20. (Additional file 1: Table S1).

Patient median age at the time of treatment switch was 47 (range 22-82 years) and 55 years (range 33-78) in the NILO and DASA group, respectively $(p=0.035)$. Median duration of IMA therapy for the overall population, before receiving second line therapy, was 2.3 years. Median time from treatment change to study survey was 2.75 years. No differences in the main reason for switching from IMA 
Table 1 Physician-reported reasons for choosing the 2nd line drug

\begin{tabular}{|c|c|c|c|c|}
\hline Variable & Nilotinib & Dasatinib & Totaln (\%) & $p$-value(2 sided) \\
\hline \multicolumn{5}{|c|}{ Accessibility of the drug in physician institution } \\
\hline Not at all & $34(94.44)$ & $29(93.55)$ & $63(94.03)$ & 1 \\
\hline Very much & $2(5.56)$ & $2(6.45)$ & $4(5.97)$ & \\
\hline \multicolumn{5}{|l|}{ Cost of drug } \\
\hline Not at all & $33(91.67)$ & $29(93.55)$ & $62(92.54)$ & 0.081 \\
\hline A little & $3(8.33)$ & $0(0)$ & $3(4.48)$ & \\
\hline Quite a bit & $0(0)$ & $2(6.45)$ & $2(2.99)$ & \\
\hline \multicolumn{5}{|c|}{ Patient comorbidity profile } \\
\hline Not at all & $15(41.67)$ & $13(41.94)$ & $28(41.79)$ & 0.977 \\
\hline A little & $6(16.67)$ & $4(12.9)$ & $10(14.93)$ & \\
\hline Quite a bit & $13(36.11)$ & $13(41.94)$ & $26(38.81)$ & \\
\hline Very much & $2(5.56)$ & $1(3.23)$ & $3(4.48)$ & \\
\hline \multicolumn{5}{|l|}{ Patient's age } \\
\hline Not at all & $18(50)$ & $13(41.94)$ & $31(46.27)$ & 0.797 \\
\hline A little & $5(13.89)$ & $7(22.58)$ & $12(17.91)$ & \\
\hline Quite a bit & $11(30.56)$ & $10(32.26)$ & $21(31.34)$ & \\
\hline Very much & $2(5.56)$ & $1(3.23)$ & $3(4.48)$ & \\
\hline \multicolumn{5}{|c|}{ Patient's personality profile } \\
\hline Not at all & $9(25)$ & $11(35.48)$ & $20(29.85)$ & 0.534 \\
\hline A little & $7(19.44)$ & $8(25.81)$ & $15(22.39)$ & \\
\hline Quite a bit & $18(50)$ & $10(32.26)$ & $28(41.79)$ & \\
\hline Very much & $2(5.56)$ & $2(6.45)$ & $4(5.97)$ & \\
\hline \multicolumn{5}{|c|}{ Previous discussion about Pros and Cons of both treatments } \\
\hline Not at all & $5(13.89)$ & $3(9.68)$ & $8(11.94)$ & 0.455 \\
\hline A little & $3(8.33)$ & $7(22.58)$ & $10(14.93)$ & \\
\hline Quite a bit & $24(66.67)$ & $18(58.06)$ & $42(62.69)$ & \\
\hline Very much & $4(11.11)$ & $3(9.68)$ & $7(10.45)$ & \\
\hline \multicolumn{5}{|c|}{ Different treatment schedules } \\
\hline Not at all & $21(58.33)$ & $13(41.94)$ & $34(50.75)$ & 0.615 \\
\hline A little & $6(16.67)$ & $7(22.58)$ & $13(19.4)$ & \\
\hline Quite a bit & $7(19.44)$ & $8(25.81)$ & $15(22.39)$ & \\
\hline Very much & $2(5.56)$ & $3(9.68)$ & $5(7.46)$ & \\
\hline \multicolumn{5}{|c|}{ Type of mutation during IM therapy } \\
\hline Not at all & $31(86.11)$ & $26(83.87)$ & $57(85.07)$ & 0.460 \\
\hline Quite a bit & $4(11.11)$ & $2(6.45)$ & $6(8.96)$ & \\
\hline Very much & $1(2.78)$ & $3(9.68)$ & $4(5.97)$ & \\
\hline
\end{tabular}

therapy (intolerance or resistance) or in the occurrence of any grade 3 or 4 AEs during previous IMA therapy were found between the groups of patients treated with NILO and with DASA. Physicians' evaluation on factors that guided their decisions to switch patients to one of the two drugs was not different by type of second line therapy actually chosen (i.e., either NILO or DASA). The most relevant determinant for 2 nd line TKI selection was 'previous discussion with patients on pros and cons of drugs', being reported as "quite a bit" or "very much" important in $73 \%$ of all evaluations. Patient's comorbidity or personality profile, was quoted as a 'quite a bit' or 'very much' relevant reason for the selection of 2 nd line TKI, respectively in $43 \%$ and $48 \%$ of all questionnaires. In spite of different prices, the cost of the drug was not considered relevant at all, in the selection of which drug to use, in $93 \%$ of the 67 evaluations considered, but it should not be overlooked that both TKIs, for many of these patients, were provided free-of-charge by the national health system. Low relevance was assigned to patient age, but patients switched to NILO were older than those switched to DASA, and to different treatment schedule: 'not at all' or 'a little' relevance was reported respectively in $64 \%$ and $70 \%$ of all questionnaires (Table 1). No statistically significant differences were found in selected factors, driving the decision to switch either to NILO or DASA when physicians considered switching from first line IMA therapy.

The results of this pilot survey on potential determinants for the second line TKI choice in CML showed that physicians consider discussion with their patients about advantages and disadvantages of drugs, as the most relevant factor based on which making a decision. Since the choice of the physicians is usually guided by technical and professional considerations, this suggests that the available data on efficacy, safety, and cost, were not sufficient, or were not sufficiently different, to allow a priority of physicians' over patients' choice. There is paucity of evidence on how such decisions are made in routine CML care and our study underscores the need of further research in this area, including prospective randomized comparative studies.

\section{Additional file}

Additional file 1: Table S1. Physician characteristics. (DOCX $15 \mathrm{~kb}$ )

Abbreviations

CML: Chronic myeloid leukemia; DASA: Dasatinib; IMA: Imatinib; NILO: Nilotinib; TKI: Tyrosine kinase inhibitors

\author{
Acknowledgements \\ Not applicable. \\ Funding \\ Not applicable.
}

Availability of data and materials

The datasets used and/or analysed during the current study are available from the corresponding author on reasonable request.

Authors' contributions

MB, FE: conception and design. All authors: acquisition and interpretation of data, drafting of manuscript. All authors read and approved the final manuscript.

Ethics approval and consent to participate

The study was approved by the Sapienza University of Rome Ethics Committee and by other participating centers. 
Informed consent was obtained from all individual participants included in the study. All procedures followed were in accordance with the ethical standards of the responsible committee on human experimentation (institutional and national) and with the Helsinki Declaration of 1975, as revised in 2008.

\section{Consent for publication}

Not applicable.

\section{Competing interests}

Massimo Breccia: speaker fees Novartis, Bristol-Myers Squibb, Pfizer and Incyte. Michele Baccarani: speaker fees Bristol-Myers Squibb and Novartis. Gianantonio Rosti: speaker bureau for Novartis, Bristol-Myers Squibb, Pfizer e Incyte. Fabio Efficace: Consultancy: Bristol-Myers Squibb, Seattle Genetics, TEVA and Incyte; Research funding: Lundbeck, TEVA and Amgen.

\section{Publisher's Note}

Springer Nature remains neutral with regard to jurisdictional claims in published maps and institutional affiliations.

\section{Author details}

'Department of Biotechnologies and Hematology, University of Rome Sapienza, Rome, Italy. ${ }^{2}$ Department of Hematology-Oncology, University of Bologna, S. Orsola-Malpighi Hospital, Bologna, Italy. I'talian Group for Adult Hematologic Diseases (GIMEMA), Data Center and Health Outcomes Research Unit, Rome, Italy. ${ }^{4}$ Inserm CIC 1402 , CHU de Poitiers, Poitiers, France.

Received: 15 June 2017 Accepted: 13 October 2017 Published online: 18 October 2017

\section{References}

1. Deininger M, O'Brien SG, Guilhot F, Goldman JM, Hochhaus A, Hughes TP, Radich JP, Hatfield AK, Mone M, Filian J, et al. International randomized study of interferon Vs STI571 (IRIS) 8-year follow up: sustained survival and low risk for progression or events in patients with newly diagnosed chronic myeloid leukemia in chronic phase (CML-CP) treated with Imatinib. Blood. 2009;1 14:462

2. Cortes J, Talpaz M, O'Brien S, Jones D, Luthra R, Shan J, Giles F, Faderl S, Verstovsek S, Garcia-Manero G, et al. Molecular responses in patients with chronic myelogenous leukemia in chronic phase treated with imatinib mesylate. Clin Cancer Res. 2005;11:3425-32.

3. Marin D, Ibrahim AR, Lucas C, Gerrard G, Wang L, Szydlo RM, Clark RE, Apperley JF, Milojkovic D, Bua M, et al. Assessment of BCR-ABL1 transcript levels at 3 months is the only requirement for predicting outcome for patients with chronic myeloid leukemia treated with tyrosine kinase inhibitors. J Clin Oncol. 2012;30:232-8.

4. Hanfstein B, Muller MC, Hehlmann R, Erben P, Lauseker M, Fabarius A, Schnittger S, Haferlach C, Gohring G, Proetel U, et al. Early molecular and cytogenetic response is predictive for long-term progression-free and overall survival in chronic myeloid leukemia (CML). Leukemia. 2012;26:2096-102.

5. Castagnetti F, Di Raimondo F, De Vivo A, Spitaleri A, Gugliotta G, Fabbiano F, Capodanno I, Mannina D, Salvucci M, Antolino A, et al. A populationbased study of chronic myeloid leukemia patients treated with imatinib in first line. Am J Hematol. 2017;92:82-7.

6. Jabbour E, Cortes J, Kantarjian H. Long-term outcomes in the second-line treatment of chronic myeloid leukemia: a review of tyrosine kinase inhibitors. Cancer. 2011;117:897-906.

7. Jabbour E, Kantarjian H, Cortes J. Use of second- and third-generation tyrosine kinase inhibitors in the treatment of chronic myeloid leukemia: an evolving treatment paradigm. Clin Lymphoma Myeloma Leuk. 2015;15:323-34.

8. Hochhaus A, Ernst T, Eigendorff E, La Rosee P. Causes of resistance and treatment choices of second- and third-line treatment in chronic myelogenous leukemia patients. Ann Hematol. 2015;94(Suppl 2):S133-40.

9. Efficace F, Baccarani M, Breccia M, Alimena G, Rosti G, Cottone F, Deliliers $G L$, Baratè C, Rossi AR, Fioritoni G, et al. Health-related quality of life in chronic myeloid leukemia patients receiving long-term therapy with imatinib compared with the general population. Blood. 2011;118:4554-60.

10. Efficace F, Baccarani M, Breccia M, Saussele S, Abel G, Caocci G, Guilhot F, Cocks K, Naeem A, Sprangers M, et al. International development of an EORTC questionnaire for assessing health-related quality of life in chronic myeloid leukemia patients: the EORTC QLQ-CML24. Qual Life Res. 2014;23:825-36.

\section{Submit your next manuscript to BioMed Central and we will help you at every step:}

- We accept pre-submission inquiries

- Our selector tool helps you to find the most relevant journal

- We provide round the clock customer support

- Convenient online submission

- Thorough peer review

- Inclusion in PubMed and all major indexing services

- Maximum visibility for your research

Submit your manuscript at www.biomedcentral.com/submit
Biomed Central 